\title{
Recursos didácticos digitales: medios innovadores para el trabajo colaborativo en línea
}

\author{
Elionay Quirós Meneses ${ }^{l}$ \\ Profesor de la División de Educología \\ Centro de Investigación y Docencia en Educación, Universidad Nacional \\ Heredia, Costa Rica
}

Recibido 19 de agosto de 2008 • Aceptado 29 de abril de 2009

Resumen. El propósito de este escrito es dar a conocer el origen, las características y las reglas de Blog, Wiki, Chat, Foro y la herramienta Cmap Tools, aspectos fundamentales para un adecuado uso de estos recursos digitales. Además, el principal aporte que se brinda es explicitar los usos didácticos posibles que ofrecen estos recursos, como una propuesta estratégica dinámica para el trabajo colaborativo en línea.

Palabras clave. Recursos didácticos digitales, Tecnologías de la Información y Comunicación, educación en línea.

Abstract. The purpose of this paper is to present the origin, characteristics and rules of the Blogs, Wikis, Chats, Forums, and the Cmap Tools, that one must take into account when working with them as digital resources. In addition, the main contribution offered, is an explanation of possible didactic uses that these resources offer as a dynamic strategic proposal for collaborative e-learning.

Key words. Digital didactic resources, Information and Communication Technologies, e-learning.

1 Profesor de la Universidad Nacional de Heredia, Costa Rica desde el año 2008. Máster en Tecnología e Informática Educativa de la Universidad Nacional de Costa Rica. Bachiller en Ciencias de la Educación con Énfasis en Educación Rural I y II ciclo. Un año de estudios en la carrera de Filosofía.

Correo electrónico: equiroster@gmail.com 


\section{Introducción}

El foco de atención en los últimos años, es la aparición y el avance acelerado de las Tecnologías de la Información y Comunicación (TICs), realidad que, sin duda, conlleva al replanteamiento de nuevas estrategias y técnicas en los procesos de enseñanza y de aprendizaje, en los que, de manera particular, se incrementa el aprendizaje en línea.

En la actualidad, la tecnología, y especialmente la Internet, se ha convertido en un medio potencial que ofrece un sinnúmero de recursos digitalizados en línea, los que, si bien es cierto, son recursos que han sido creados para diversas actividades, y a pesar de que el no han sido creados con la intención de ponerlos en práctica en el campo educativo, poco a poco, con el trascurrir del tiempo, se han convertido en medios para potenciar la educación, gracias a que el ser humano ha puesto en práctica sus habilidades.

Ésta es la razón por la que las universidades están proponiendo cambios metodológicos y estratégicos en la educación a distancia, de tal forma que se pueda estar acorde con la realidad de nuestros tiempos. Por eso, es que, por ejemplo, vemos que en diferentes partes del mundo (en algunos países más que en otros) están promoviendo el uso de estos recursos digitales en gran escala, gracias a las ventajas que nos ofrecen, tales como la reducción de costos y de tiempo.

Con el objetivo de ubicar al lector, en este trabajo se presenta una conceptuación, la reseña histórica, las características y las reglas que se deben tener en cuenta en el uso de Blog, Wiki, Chat, Foro y la herramienta Cmap Tools, y finalmente para llegar a una propuesta que permita conocer algunos aportes del uso de estos recursos digitales en el proceso educativo.

Los profesionales que conforman la gran red de educadores deben enfrentar los avances y los retos que nos ofrece y demanda la sociedad, y las tecnologías son, precisamente, parte de los desafíos en los que nos encontramos inmersos. Esta propuesta hace énfasis en recursos tecnológicos que se fundamentan en el trabajo colaborativo, y como todos ellos pueden encontrarse en línea en sitios gratuitos, es que se ofrecen algunas estrategias que pueden ser consideradas en el momento de la planificación pedagógica de los cursos.

\section{Recursos digitales}

El Internet o la red de redes, como también se le ha llamado, es un medio que ofrece una gran diversidad de recursos digitales para un sinfín de usos y que poseen características diferentes, por lo que ha sido necesario clasificarlos de acuerdo con el medio para el cual han sido creados.

Para Townsend (2000), éstos se clasifican en tres grupos, a saber:

a. Transmisivos, que son los que apoyan el envío, de manera efectiva, de mensajes del emisor a los destinarios.

b. Activos, que permiten que el aprendiente actúe sobre el objeto de estudio, y, a partir de esta experiencia y reflexión, construya sus conocimientos.

c. Interactivos, cuyo objetivo es que el aprendizaje se dé a partir de un diálogo constructivo, sincrónico o asincrónico, entre individuos que usan medios digitales para comunicar e interactuar.

Para una mejor comprensión, en la siguiente tabla, se exponen algunos recursos digitales que pertenecen a los tres grupos citados anteriormente. 
Tabla 1

Clasificación y ejemplos de recursos tecnológicos

\begin{tabular}{|c|c|}
\hline Tipo & Descripción o ejemplos \\
\hline Transmisivos & $\begin{array}{l}\text { - Bibliotecas digitales, videotecas digitales, audiotecas digitales, enciclopedias } \\
\text { digitales. } \\
\text { - Tutoriales para apropiación y afianzamiento de contenidos. } \\
\text { - Sitios en la red para recopilación y distribución de información. } \\
\text { - Sistemas para reconocimiento de patrones (imágenes, sonidos, textos, voz). } \\
\text { - Sistemas de automatización de procesos, que ejecutan lo esperado. }\end{array}$ \\
\hline Activos & $\begin{array}{l}\text { - } \text { Modeladores de fenómenos o de micromundos. } \\
\text { - } \text { Simuladores de procesos o de micromundos. } \\
\text { - Juegos individuales de: creatividad, habilidad, competencia, roles. } \\
\text { - Sistemas expertos en un dominio de contenidos. } \\
\text { - Traductores y correctores de idiomas, decodificadores de lenguaje natural. } \\
\text { - Agentes inteligentes: buscadores y organizadores con inteligencia. } \\
\text { - Herramientas de productividad: procesador de texto, hoja de cálculo, procesador } \\
\text { - gráfico, organizador de información. } \\
\text { Herramientas multimediales creativas: editores de hipertextos, de películas, de } \\
\text { sonidos o de música. }\end{array}$ \\
\hline Interactivos & $\begin{array}{l}\text { - Juegos en la red, colaborativos o de competencia, con argumentos cerrados o } \\
\text { abiertos, en dos o tres dimensiones. } \\
\text { - Sistemas de mensajería electrónica (MSN, AIM, ICQ), pizarras electrónicas, } \\
\text { programas de videoconferencias en línea, así como ambientes de CHAT textual o } \\
\text { multimedial (video o audioconferencia) que permiten hacer diálogos sincrónicos. } \\
\text { - Sistemas de correo electrónico textual o multimedial, sistemas de foros electrónicos, } \\
\text { blogs, wikis, moderados o no moderados, que permiten hacer diálogos e interactuar, } \\
\text { asincrónicamente. }\end{array}$ \\
\hline
\end{tabular}

Nota: Creación personal, de acuerdo con la clasificación de Townsend (2000).

De acuerdo con esta clasificación, los primeros dos tipos adquieren la misma importancia, según sea el objetivo en un contexto educativo particular en que sean puestos en práctica. Para efectos de análisis, en este trabajo se hace énfasis en los recursos interactivos, ya que ofrece un mayor intercambio entre los usuarios, por medio de la participación que ellos ofrezcan, según la metodología planteada que se proponga. Además, por la flexibilidad y la manera en que se puede interactuar en cada uno de estos recursos, es que se pueden lograr aprendizajes significativos. Sin duda, la creatividad es un factor determinante que despierta el deseo y la motivación en el proceso de ese aprendizaje. 
Con base en lo anterior, es que ha sido fundamental detallar al menos cinco recursos didácticos digitales que muestran una evolución con mayor rapidez en el campo educativo; además de que son sencillos, amigables y de fácil manipulación. Un factor esencial para la elección es que son recursos que potencian la educación a distancia.

Gracias a estos recursos, el deseo por aprender se vuelve cada vez mayor en los estudiantes, porque, ante todo, estimulan el aprendizaje colaborativo y propician la participación, la creatividad y el desarrollo del pensamiento crítico. Estos recursos didácticos digitales requieren y permiten nuevas estrategias didácticas acordes con cada contexto educativo. Los recursos seleccionados son el Blog, el Wiki, el Chat, el Foro y el CmapTools.

Históricamente, los recursos digitales han evolucionado de acuerdo con las necesidades y los intereses de la sociedad, así también, por la creatividad y la imaginación, aspectos que el ser humano ha experimentado conforme se ha ido dando cuenta del potencial que ofrece la Internet. Es por ello, que a continuación se conocerá el nacimiento y el motivo por el cual se creó cada uno de estos recursos digitales, que se exponen a través de las páginas de este documento.

\section{El Blog}

Fue creado en abril de 1997 por Dave Winer, quien edita el Scripting News, que era una bitácora de tecnología y de política. Esto ocurrió en los Estados Unidos.

La intención de crearlo fue el tener una herramienta para llevar un registro acerca de situaciones o acciones ejecutadas por una persona, y, así, garantizar un orden de las cosas que se van haciendo. Además, en su inicio, los Blogs, o bien, bitácoras, como se traduce al español, contaban con las posibilidades mínimas de llevar los registros. En muy poco tiempo, esta herramienta de publicación se ha extendido a través de todo el mundo, y ha permitido que los pensamientos y las opiniones del ser humano puedan llegar a tener una influencia en los medios de comunicación. Asimismo, se les ha otorgado un panorama más dinámico, lo que posibilita la creación de vínculos con otros sitios, insertar vídeos, imágenes y audio, entre otros (Escamilla, 2003).

La importancia de la comunidad de Blogs, y su relación con una sociedad más grande, cobró importancia rápidamente.

\section{El Wiki}

El primero fue creado por el programador Ward Cunningham, quien lo llamó WikiwikiWeb. Él mismo, produjo la primera implementación de un servidor Wiki para el repositorio de patrones Portland, en 1995. Así, la necesidad de compartir en línea un documento, abierto a las modificaciones y sugerencias de un grupo de colaboradores llegó desde el momento de su creación.

\section{El Chat}

Nace en el año 1972, cuando se logró la primera conversación de computadora a computadora, entre un paciente y un psiquiatra. Pero es hasta el año 1988, que Jarkko Oikarinen escribe el código. En un primer momento, esta persona diseñó el Chat para usarlo en su empresa como un sistema Multichat, en tiempo real, entre los compañeros del trabajo por medio de una red local. 
Una vez que la Internet se fue extendiendo y, sobre todo, cuando Oikarinen comenzó a utilizarlo como medio de apoyo para la comunicación fuera de la empresa con otros usuarios, el sistema comenzó a popularizarse aceleradamente, y fue así que pasó a convertirse en un recurso didáctico digital de comunicación, se puede decir, indispensable para todos aquellos que necesitaban comunicarse de una manera más continua y segura.

Fue hasta el año 1991, que este recurso llamado por sus siglas IRC y que en inglés se domina Internet Relay Chat, o bien, Charla conmutada en Internet, tomó un mayor impulso, debido a la necesidad de comunicación cuando, precisamente, se desarrollaba la Guerra del Golfo.

Otra fecha importante de destacar es setiembre de 1993, cuando gran número de usuarios, en tiempo real, informaban desde Moscú sobre la inestabilidad social y política en la que se encontraba el país. Aún más: con el paso del tiempo, los avances tecnológicos han permitido que esta herramienta alcance hasta la posibilidad de hacer conversaciones mediante audio y vídeo.

\section{El Foro}

Éste es un concepto que nace de la antigua Roma, para definir el lugar en donde se trataban asuntos públicos y judiciales. En él, también, existían algunas áreas para realizar los juicios de los tribunales. El término Foro, viene del latín Forum, que significa, "Reunión para discutir asuntos de interés actual ante un auditorio, el que, a veces, interviene en la discusión."

Aunque la historia de este recurso es muy breve, se dice que éstos son los descendientes de los sistemas de noticias BBS (Bulletin Board System) Usenet, muy populares durante las décadas 1980 y 1990.

En la actualidad, este recurso didáctico digital ha evolucionado a lo que hoy se conoce, en gran escala, como foros; otros les llaman foros virtuales y se reconocen como espacios que permiten a la sociedad participar, opinar y ser parte de discusiones, lo que, a su vez, se transforma en un gran aporte a la sociedad.

\section{CmapTools}

Se destaca el desarrollo de los mapas conceptuales. Éstos fueron desarrollados en 1972 y se basaron en la psicología del aprendizaje de Ausubel (citado por Vargas, 1998). La tesis propuesta por Ausubel es sobre la psicología cognitiva, la que plantea que el aprendizaje se da por la asimilación de nuevos conceptos y proposiciones en una estructura conceptual y preposicional ya existente en el estudiante. Debido a la necesidad de encontrar una mejor manera de mostrar la comprensión conceptual de niños, surgió la idea de representar el conocimiento de éstos en forma de un mapa conceptual. Así, nació una nueva herramienta llamada CmapTools, no sólo para uso en investigación, sino, también, para muchos otros ámbitos.

El programa CmapTools fue desarrollado en el Instituto de Cognición Humana y de Máquinas. Combina las fortalezas de hacer mapas conceptuales con el poder de la tecnología, particularmente la Internet. El software facilita a los usuarios de todas las edades construir y modificar mapas conceptuales, de una manera similar a la que un procesador de palabras facilita escribir un texto; asimismo, permite a los usuarios colaborar a distancia en la construcción de sus mapas y publicarlos, de manera que cualquier persona pueda accederlos en Internet, agregarle recursos a sus mapas para explicar mejor sus contenidos. 
Ahora bien, cada recurso didáctico digital tiene características y reglas propias, lo que me lleva a puntualizar algunas de ellas. En este sentido, se pretende que los lectores comprendan, fácilmente, en qué consiste y cuáles son las propiedades de cada una de estas herramientas.

Para efectos de mayor facilidad y comprensión de lectura, cada recurso se expone por separado en las siguientes tablas.

Tabla 2

El Blog

\begin{tabular}{|c|c|c|}
\hline Definición & Características & Reglas \\
\hline $\begin{array}{l}\text { Se puede decir que } \\
\text { un blog es un sitio } \\
\text { Web frecuentemente } \\
\text { actualizado, } \\
\text { que recopila, } \\
\text { cronológicamente } \\
\text { textos, vídeos, audio, } \\
\text { imágenes o artículos de } \\
\text { uno o varios autores. El } \\
\text { más reciente aparece } \\
\text { primero, con un uso o } \\
\text { temática en particular, } \\
\text { y siempre el autor } \\
\text { conserva la libertad de } \\
\text { dejar publicado lo que } \\
\text { crea pertinente. Ante } \\
\text { todo, es una forma } \\
\text { libre de expresión, de } \\
\text { creación y de compartir } \\
\text { conocimiento. }\end{array}$ & $\begin{array}{l}\text { - Cada individuo o grupo le da su } \\
\text { estilo. } \\
\text { Mediante un formulario, se } \\
\text { permite a otros usuarios de la Web } \\
\text { añadir comentarios, con lo que se } \\
\text { genera un debate alrededor de sus } \\
\text { contenidos, además de cualquier } \\
\text { otra información. } \\
\text { El autor puede permitir el acceso a } \\
\text { comentarios de otros usuarios o no. } \\
\text { Las publicaciones que se van } \\
\text { creando se encuentran fechadas } \\
\text { cronológicamente, es decir, los } \\
\text { mensajes más recientes aparecen } \\
\text { primero. } \\
\text { Es posible, además, agregar } \\
\text { fotografías, imágenes y vídeos, } \\
\text { a lo que recientemente se le ha } \\
\text { llamado Fotoblogs o Videoblogs, } \\
\text { respectivamente. } \\
\text { Cuentan con un calendario y un } \\
\text { archivo electrónico lo que permite } \\
\text { al lector acceder a los artículos que } \\
\text { se han publicado en los diferentes } \\
\text { días del mes. }\end{array}$ & $\begin{array}{l}\text { A los integrantes, se les solicita } \\
\text { que cuando participen escriban } \\
\text { su nombre y apellido para } \\
\text { identificarlos y conocer la } \\
\text { precedencia de la intervención. } \\
\text { - Utilizar apropiadamente la } \\
\text { puntuación. } \\
\text { - Respetar la opinión de todos } \\
\text { los participantes. } \\
\text { - Cualquier persona registrada } \\
\text { podrá enviar sus ideas para ser } \\
\text { publicadas, de acuerdo con las } \\
\text { modalidades indicadas. } \\
\text { - El administrador es la } \\
\text { persona quien crea su Blog } \\
\text { o, bien, los facilitadores son } \\
\text { quienes proponen criterios de } \\
\text { evaluación según sus objetivos. } \\
\text { Algunas reglas para la facilitación } \\
\text { de la lectura dentro de los Blogs } \\
\text { son: el contraste del texto con } \\
\text { el fondo, pues tienen que ser } \\
\text { opuestos, los diferentes tamaños } \\
\text { y el uso correcto de ayudas } \\
\text { visuales, tales como el uso del } \\
\text { subrayado, la negrita y los colores. }\end{array}$ \\
\hline
\end{tabular}

Nota: Creación personal, de acuerdo con las fuentes consultadas. 
Tabla 3

El Chat

\begin{tabular}{|c|c|c|}
\hline Definición & Características & Reglas \\
\hline $\begin{array}{l}\text { Es un sistema de } \\
\text { comunicación basado } \\
\text { en la mensajería } \\
\text { instantánea, que } \\
\text { permite que las } \\
\text { personas conectadas } \\
\text { se comuniquen entre } \\
\text { sí mediante la lengua } \\
\text { escrita, el audio o } \\
\text { el vídeo (Webcam) } \\
\text { y en tiempo real, } \\
\text { sin importar en qué } \\
\text { parte del mundo se } \\
\text { encuentran. }\end{array}$ & 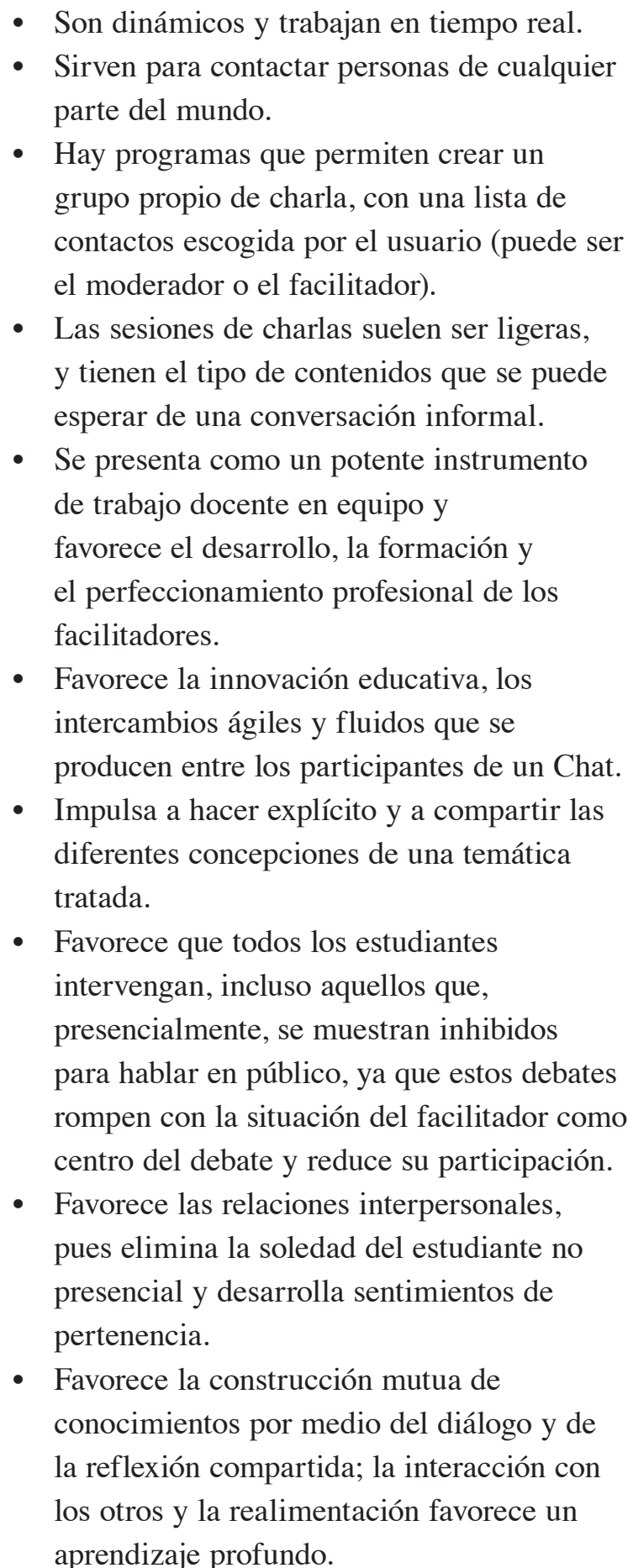 & $\begin{array}{l}\text { - Para iniciar el Chat } \\
\text { se necesita un alias } \\
\text { sobrenombre (Nickname), } \\
\text { o el nombre propio, que } \\
\text { es el nombre con el que } \\
\text { le conocerán en el Chat. } \\
\text { - Si se desea introducir } \\
\text { el Chat y discutir temas } \\
\text { acerca de los contenidos } \\
\text { en un curso específico, } \\
\text { se tiene que tomar } \\
\text { en consideración la } \\
\text { puesta en práctica de } \\
\text { este recurso didáctico } \\
\text { digital con suficiente } \\
\text { tiempo, de tal forma que } \\
\text { los estudiantes estén } \\
\text { preparados y organizados } \\
\text { con antelación. } \\
\text { Existen tres etapas } \\
\text { contempladas en la } \\
\text { planificación: } \\
\text { a) Previa } \\
\text { b) Desarrollo y } \\
\text { c) Cierre }\end{array}$ \\
\hline
\end{tabular}

Nota: Creación personal, de acuerdo con las fuentes consultadas. 
Tabla 4

El Wiki

\begin{tabular}{|c|c|c|}
\hline Definición & Características & Reglas \\
\hline $\begin{array}{l}\text { Son grupos de } \\
\text { comunidades } \\
\text { virtuales que } \\
\text { comparten un } \\
\text { interés común, } \\
\text { y se constituyen } \\
\text { para formar un } \\
\text { conocimiento } \\
\text { especializado } \\
\text { con aprendizajes } \\
\text { basados sobre } \\
\text { experiencias } \\
\text { prácticas, a partir } \\
\text { de una aplicación } \\
\text { en Internet que } \\
\text { permite a los } \\
\text { usuarios agregar } \\
\text { contenidos } \\
\text { en un mismo } \\
\text { documento. } \\
\text { Pueden ser } \\
\text { editados y } \\
\text { consultados. }\end{array}$ & $\begin{array}{l}\text { - Un Wiki permite la creación colectiva } \\
\text { de documentos en un lenguaje simple } \\
\text { de marcas, que se escribe mediante una } \\
\text { sintaxis, utilizando un navegador Web. } \\
\text { - Las versiones antiguas de los documentos } \\
\text { nunca se eliminan, y pueden restaurarse. } \\
\text { - No se necesita aprender un nuevo } \\
\text { programa para escribir en él. Es muy } \\
\text { parecido a un editor de texto. No es } \\
\text { necesario tener grandes conocimientos } \\
\text { informáticos. } \\
\text { - Se modifica la información directamente } \\
\text { en Internet (no hay que subir toda la Web } \\
\text { modificada). } \\
\text { - La carga de trabajo no recae sobre una } \\
\text { única persona. } \\
\text { - La Web enriquece muy rápido. } \\
\text { Hace que la Web sea más neutral, pues } \\
\text { presenta más puntos de vista. } \\
\text { El hecho de que el mantenimiento sea } \\
\text { sencillo y que muchos usuarios puedan } \\
\text { contribuir en forma colaborativa, hace } \\
\text { que la Web sea muy dinámica y esté } \\
\text { siempre actualizada. } \\
\text { Este tipo de software permite la edición } \\
\text { simultánea de un texto (o un archivo } \\
\text { de audio, de vídeo o de multimedia) } \\
\text { por un grupo de participantes en una } \\
\text { comunidad. } \\
\text { En el campo pedagógico, impacta cuando } \\
\text { se trata de trabajos en equipo, creación } \\
\text { de proyectos y permite clases sincrónicas } \\
\text { a distancia. }\end{array}$ & $\begin{array}{l}\text { - Ser preciso para evitar } \\
\text { ambigüedad. } \\
\text { El uso de material con } \\
\text { copyright, en los artículos está, } \\
\text { estrictamente, prohibido. } \\
\text { - No se debe suponer que el } \\
\text { recién llegado actúa con } \\
\text { mala fe; es probable que los } \\
\text { errores que comete se deben } \\
\text { a la inexperiencia, y que, } \\
\text { sinceramente, esté decidido a } \\
\text { colaborar. } \\
\text { No se debe eliminar material } \\
\text { útil; siempre y cuando sea } \\
\text { en realidad útil. Si hay un } \\
\text { problema con algún contenido, } \\
\text { uno debería editarlo de modo } \\
\text { que se acabe con el problema; } \\
\text { o, en algunos casos especiales, } \\
\text { algunos de los estudiantes o } \\
\text { el facilitador deciden mover el } \\
\text { contenido, temporalmente, a } \\
\text { páginas de discusión de donde, } \\
\text { con posterior atención, puede ser } \\
\text { borrado. } \\
\text { En el Wiki no es, estrictamente } \\
\text { necesario que el estudiante cite } \\
\text { las fuentes de las que obtiene la } \\
\text { información; sin embargo, es una } \\
\text { buena práctica destacarlas cada } \\
\text { vez que se pueda. Si se usa un } \\
\text { libro o libros para escribir sobre } \\
\text { un tema, hay que mencionarlos } \\
\text { con el título de Referencias. Si } \\
\text { se usa información de un sitio } \\
\text { Web, hay que mencionarlos con } \\
\text { el título de Enlaces externos. } \\
\text { Así, los lectores pueden verificar } \\
\text { lo que se ha escrito y buscar más } \\
\text { información al respecto. }\end{array}$ \\
\hline
\end{tabular}

Nota: Creación personal, de acuerdo con las fuentes consultadas. 
Tabla 5

El Foro

\begin{tabular}{|c|c|c|}
\hline Definición & Características & Reglas \\
\hline $\begin{array}{l}\text { Un foro es } \\
\text { una aplicación } \\
\text { en Internet y } \\
\text { es conocido } \\
\text { como foro de } \\
\text { mensajes de } \\
\text { opinión o foro } \\
\text { de discusión, y } \\
\text { le da soporte } \\
\text { a discusiones } \\
\text { u opiniones en } \\
\text { línea. } \\
\text { Representa un } \\
\text { segmento de } \\
\text { la sociedad } \\
\text { donde un grupo } \\
\text { de personas } \\
\text { mantienen } \\
\text { conversaciones } \\
\text { más o menos } \\
\text { en torno a } \\
\text { un tema de } \\
\text { actualidad. }\end{array}$ & $\begin{array}{l}\text { - Se puede configurar, } \\
\text { adecuadamente, el número de } \\
\text { mensajes que se desean tener } \\
\text { activos en el Foro. } \\
\text { - Mediante el panel de control es } \\
\text { posible borrar mensajes de forma } \\
\text { colectiva, así como desde el mismo } \\
\text { foro, si el diseño lo permite. } \\
\text { - Se prohíbe la entrada a usuarios } \\
\text { inconvenientes, y se puede } \\
\text { configurar para ellos una } \\
\text { prohibición total de acceso, } \\
\text { de escritura y de duración, } \\
\text { dependiendo del caso. También } \\
\text { es posible dar acceso sólo a } \\
\text { determinados usuarios. } \\
\text { Notificación de respuestas al } \\
\text { usuario cuando alguno opina. } \\
\text { El administrador recibe todos los } \\
\text { mensajes insertados por correo. } \\
\text { Es posible crear foros adicionales } \\
\text { que funcionarán con la } \\
\text { configuración del principal. } \\
\text { Se denegará la entrada a mensajes } \\
\text { que contengan alguna palabra de } \\
\text { una lista que se ha establecido, } \\
\text { previamente, como indeseable o no } \\
\text { de línea. Existen varios diseños } \\
\text { predeterminados que facilitan la } \\
\text { personalización a partir de uno de } \\
\text { ellos o desde cero. }\end{array}$ & $\begin{array}{l}\text { Es preciso mantener respeto } \\
\text { a los usuarios del Foro, a los } \\
\text { moderadores quienes son personas } \\
\text { que tienen una labor dentro del } \\
\text { Foro, a los administradores quienes } \\
\text { son las personas que tienen a cargo } \\
\text { el Foro en su aspecto técnico- } \\
\text { administrativo. } \\
\text { - Se prohíbe que los estudiantes } \\
\text { publiquen temas diferentes al } \\
\text { propuesto para el Foro. } \\
\text { Los títulos de temas no deben } \\
\text { abusar de letras mayúsculas. } \\
\text { No se permiten las respuestas que } \\
\text { deformen el Foro. } \\
\text { - Se prohíbe el Foro-Chat en todos } \\
\text { los Foros. Enciéndase como los } \\
\text { Foro-Chat, las ponencias entre dos } \\
\text { o más estudiantes que basan sus } \\
\text { respuestas en consecuencia de la } \\
\text { respuesta del otro, y no sobre el } \\
\text { tema en cuestión, simulando un } \\
\text { Chat. } \\
\text { Los Foros son totalmente } \\
\text { independientes unos de otros, tanto } \\
\text { en reglas como en su estilo de } \\
\text { moderación, dependiendo de los } \\
\text { contenidos por tratar. } \\
\text { El moderador puede ser el } \\
\text { facilitador o algún estudiante, según } \\
\text { su metodología. } \\
\text { ejemplar a los demás estudiantes } \\
\text { del foro, puesto que pertenecen a un } \\
\text { grupo que aporta. }\end{array}$ \\
\hline
\end{tabular}

Nota: Creación personal, de acuerdo con las fuentes consultadas. 
Tabla 6

CmapTools

\begin{tabular}{|c|c|c|}
\hline Definición & Características & Reglas \\
\hline $\begin{array}{l}\text { Es un programa } \\
\text { (software) } \\
\text { creado para } \\
\text { construir mapas } \\
\text { conceptuales } \\
\text { dinámicos con } \\
\text { la posibilidad } \\
\text { de modificarlos. } \\
\text { Además, permite } \\
\text { a los usuarios } \\
\text { colaborar, a } \\
\text { distancia, en la } \\
\text { construcción } \\
\text { de sus mapas, } \\
\text { publicar sus mapas } \\
\text { conceptuales, } \\
\text { de manera que } \\
\text { cualquier persona } \\
\text { pueda accederlos } \\
\text { en Internet, } \\
\text { agregarle recursos } \\
\text { a sus mapas para } \\
\text { explicar mejor } \\
\text { sus contenidos, y } \\
\text { hacer búsquedas } \\
\text { en la Web de } \\
\text { información } \\
\text { relacionada con el } \\
\text { mapa. }\end{array}$ & $\begin{array}{l}\text { Permite al usuario agregarle } \\
\text { recursos (fotos, imágenes, } \\
\text { gráficos, vídeos, esquemas, tablas, } \\
\text { textos, páginas Web u otros } \\
\text { mapas conceptuales), ubicados } \\
\text { en cualquier parte de Internet, a } \\
\text { conceptos o frases de enlace de un } \\
\text { mapa conceptual, por medio de una } \\
\text { sencilla operación de arrastrar y } \\
\text { soltar. } \\
\text { Es posible usar mapas conceptuales } \\
\text { para acceder a cualquier material } \\
\text { en formato digital, incluyendo } \\
\text { materiales preparados por la } \\
\text { misma persona que está haciendo } \\
\text { el mapa. De esta forma, los mapas } \\
\text { conceptuales pueden servir como } \\
\text { herramientas de indexación y de } \\
\text { navegación en dominios complejos } \\
\text { del conocimiento. } \\
\text { Brinda un apoyo extenso para } \\
\text { el trabajo colaborativo durante } \\
\text { la construcción de mapas } \\
\text { conceptuales. Los mapas } \\
\text { construidos con este recurso } \\
\text { didáctico pueden ser guardados } \\
\text { en servidores, de los que cualquier } \\
\text { persona en Internet puede } \\
\text { accederlos. }\end{array}$ & $\begin{array}{l}\text { Los mapas conceptuales } \\
\text { deben ser simples, y mostrar, } \\
\text { claramente, las relaciones entre } \\
\text { conceptos y/o proposiciones; } \\
\text { deben ir de lo general a lo } \\
\text { específico. } \\
\text { - Los conceptos deben ser } \\
\text { vistosos. } \\
\text { - Un mapa conceptual es una } \\
\text { forma breve de representar } \\
\text { información. } \\
\text { Los errores en los mapas se } \\
\text { generan si las relaciones entre los } \\
\text { conceptos son incorrectas. } \\
\text { Para elaborar mapas } \\
\text { conceptuales se requiere saber la } \\
\text { información y los conocimientos } \\
\text { (conceptos) con los que se va } \\
\text { a trabajar, ya que si no conoce } \\
\text { el tema o tiene conceptos } \\
\text { desacertados, esto puede crear } \\
\text { una representación gráfica } \\
\text { arbitraria, ilógica o errónea. } \\
\text { Se hace necesario que previo } \\
\text { a la realización de su mapa } \\
\text { conceptual, el estudiante haya } \\
\text { entendido los conceptos claves } \\
\text { de un tema determinado, } \\
\text { además, de haber razonado las } \\
\text { relaciones existentes. }\end{array}$ \\
\hline
\end{tabular}

Nota: Creación personal, de acuerdo con las fuentes consultadas.

Cabe destacar que para el uso de estos recursos tecnológicos, la criticidad es un elemento esencial, sobre todo, en el aporte que nos ofrecen en el campo educativo, pues hay que ser conscientes de que la tecnología, difícilmente, puede sustituir la labor del docente; ni mucho menos, garantizar una adecuada aplicabilidad de éstos en un curso o programa si realmente no hay claridad en la 
forma que se pueda abordar y del aporte que ofrezca como medio didáctico en la enseñanza; vale recordar que las tecnologías y cualesquiera de estos recursos digitales son un medio que facilitan la labor docente y no un fin. Es decir, un recurso por sí mismo, es sólo un objeto.

El ser humano, sin duda, continúa siendo el protagonista absoluto en el proceso; los recursos digitales no son más que herramientas útiles a las que se recurre en función de las necesidades. La manera en que se emplean estos recursos, es lo que permite determinar su efectividad (Basterrechea, 2007, s. p.). Otro aspecto fundamental en la integración de los recursos digitales en ambientes educativos, es que surgen enfoques en el proceso de aprendizaje en línea, por lo que es conveniente que en el caso del facilitador, tenga conocimientos previos acerca de éstos.

En la línea de los recursos didácticos digitales, se pueden encontrar tanto elementos que favorecen el uso y el proceso de aprendizaje en línea, como factores que pueden convertirse en situaciones de aprendizaje que conllevan a una mala praxis de estos recursos.

Algunas ventajas o elementos que favorecen este proceso de aprendizaje colaborativo en línea, son las siguientes:

a. El estudiante tiene un espacio en el que puede participar dando sus opiniones o sus criterios, de acuerdo con su ritmo y con su nivel de aprendizaje.

b. Permite flexibilidad de horario, es decir, puede entrar a cualquier hora, siempre y cuando tenga acceso a Internet.

c. Hay mayor posibilidad de expresión, ya que hay personas que en una clase presencial tiene poca participación. A veces, porque son poco expresivos o porque son tímidos en su comportamiento.

d. Ayudan a fomentar el aprendizaje constructivista, es decir, el alumno construye un conocimiento propio.

e. Despiertan el interés y la motivación por aprender, porque es algo nuevo que estimula sus sentidos con imágenes, sonidos, diseños creativos, y, por tanto, se convierte en algo más atractivo.

f. Sin duda, estos recursos destacan la colaboración e interacción entre estudiantes y facilitadores.

g. Permiten una evaluación más formativa, en la que se toman más en cuenta los procesos que los resultados; aunque, de igual manera, se puede hacer evaluación cuantitativa.

h. Se eliminan las barreras de tiempo y de espacio, pues no necesita desplazarse para interactuar con sus compañeros(as) y dar sus aportes.

i. Es posible encontrar respuestas innovadoras y mejor estructuradas, ya que el estudiante tiene más tiempo para pensar lo que escribe.

Asimismo, nos enfrentamos a algunos factores o aspectos negativos. Algunos de ellos son:

a. Se va perdiendo el contacto humano. De hecho, es una de las preocupaciones en la que el ser humano se encuentra, ya que, en este sentido, se van perdiendo los valores y los principios que sólo se pueden vivir en sociedad.

b. A pesar del avance acelerado de las tecnologías de la información y la comunicación, no todas las personas tenemos acceso siquiera a una computadora o a Internet.

c. Con el uso de los recursos tecnológicos, si no se tiene, al menos, conocimientos previos sobre informática, es posible encontrarse con frustraciones que le desmotiven a participar. 
d. Finalmente, por la diversidad que ofrece la Internet, estos medios de apoyo se pueden convertir en herramientas que pueden ser distractoras en el aprendizaje y, como consecuencia, no se logran los objetivos propuestos.

La integración de recursos didácticos digitales y de sistemas de comunicación en la red, aplicados en la educación, están marcando líneas en la evolución de los actuales modelos educativos. En virtud de estas circunstancias, es urgente que la sociedad se forme y se actualice en el área de las TICs. Y es que, aunque muchas personas se resistan al cambio de enfrentar a una sociedad postmoderna, nos encontramos inmersos en una sociedad digitalizada. Por esto, debido al rol que juegan los formadores en el proceso educativo, éstos tienen que estar capacitándose constantemente, ya que su papel es protagónico en el proceso de aprendizaje, es decir, se convierte en un facilitador del aprendizaje, un creador de situaciones con medios innovadores que permiten al estudiante lograr los cambios de conducta y el desarrollo de habilidades. La relación facilitador-estudiante, siempre, debe propiciar que esa situación siga dándose.

\section{Algunas aplicaciones didácticas de los recursos digitales}

Es necesario hacer algunas sugerencias acerca de las múltiples posibilidades que nos ofrecen estos recursos didácticos digitales, particularmente con los aportes que pueden ofrecer tanto a los facilitadores como a los estudiantes.

A continuación se destacan cada uno de estos recursos.

\section{El Blog}

Los Blogs pueden ser utilizados a modo de portafolio de aula, como una selección deliberada de los trabajos, proyectos, investigaciones, encuestas que realiza el aprendiente. También, puede ser utilizado para dar cuenta de la historia de sus esfuerzos, su progreso, sus reflexiones o sus logros.

Asimismo, pueden usarse como espacio de creación cooperativa de contenidos; para ello, se usa la capacidad de los Blogs de tener múltiples editores y las redes sociales (entre los mismos estudiantes) para crear el contenido, en forma coordinada y grupal.

Un aspecto muy atractivo para los estudiantes, es que estos Blogs pueden adquirir la forma de una revista o una publicación. Además, tanto los facilitadores como los estudiantes pueden difundir actividades académicas, eventos, congresos, conferencias, con beneficio para sí mismos y para la población interesada. Esto es fundamental, ya que las instituciones educativas, pueden dar a conocer, de forma ágil y sencilla, este tipo de actividades.

\section{El Wiki}

Algunas aplicaciones que se le pueden dar al Wiki es la construcción de contenidos por medio de la participación de un grupo de estudiantes.

Específicamente, los facilitadores pueden crear un espacio con esta herramienta en el que puedan leer, analizar, discutir o imprimir los apuntes. Además, mediante este recurso didáctico 
digital se pueden crear los Mundos virtuales, que son espacios donde se puede realizar una serie de actividades educativas muy variadas dentro de la red.

Otro aspecto es que con el uso de un Wiki, los estudiantes, por medio de discusiones acerca de una temática, pueden llegar a acuerdos, crear artículos, ponencias, entre otros. En el caso del educador, puede dar un seguimiento de los aportes de cada estudiante en forma cronológica, para su posterior evaluación.

\section{El Chat}

Este recurso didáctico digital se presenta como un potente instrumento de trabajo en equipo, el cual favorece el desarrollo, la formación y el perfeccionamiento profesional de los facilitadores y de los estudiantes; además, promueve y fortalece los intercambios ágiles y fluidos que se producen entre los participantes.

Así, también, impulsa a explicitar y a compartir las diferentes concepciones de la temática tratada, facilita la labor tutorial de los facilitadores en los cursos en línea, estimula la actualización en la formación del facilitador, entre cuyas competencias debe figurar el conocimiento y el empleo educativo de herramientas tecnológicas.

El debate electrónico mediante el Chat, es una manera de fomentar el aprendizaje cooperativo, además de favorecer, también, el trabajo individual si, previamente, el estudiante prepara sus aportes al debate. Este tipo de debates por medio del Chat, permite un mayor tiempo de planificación que el estar cara a cara, lo que favorece intervenciones más elaboradas y complejas; además de tener la posibilidad de consultar las participaciones previas, facilita hacer una revisión total de los intercambios sostenidos.

Además, este recurso, contribuye al desarrollo del nuevo rol del facilitador, ya que el estudiante no necesita que se le planteen conocimientos inaccesibles, sino recursos para gestionar, seleccionar y analizar, críticamente, la información.

Finalmente, por medio de este recurso los estudiantes pueden construir artículos, ensayos u otro tipo de escrito, como consecuencia de los conocimientos construidos de manera grupal.

\section{El Foro}

Los Foros en la Web se convierten en una forma de ayuda y de estímulo para el aprendizaje, de una manera más dinámica. Muchas de las dudas e inquietudes pueden ser evacuadas cordialmente, usando esta herramienta fuera del proceso presencial. Así, los estudiantes pueden ayudarse en cualquier momento del día, sin tener ninguna restricción espacio-temporal, esto es positivo porque refuerza los lazos y la autoestima entre compañeros.

Este recurso didáctico digital permite, además, un ambiente de aprendizaje colaborativo y entiéndase éste como: el proceso por el que dos o más estudiantes trabajan juntos para aprender. Dentro de este contexto, el Foro es una herramienta que se adapta a todas estas posibilidades, independientemente de la ubicación geográfica de los estudiantes, lo que ofrece un aporte a la productividad en grupo.

Tras las diversas participaciones que tienen los estudiantes dentro del Foro, se obtiene un cúmulo de aportes, con lo que el facilitador puede evaluar la calidad y profundidad de ellos, pues, como es lógico, en los foros queda constancia de la participación y de los aportes de cada uno de los estudiantes. 
Entre las aplicaciones didácticas que permite el foro, destaca que el facilitador permita, dentro de una determinada temática general, que el grupo se organice y proponga un tema de interés general, además de un moderador del Foro y se opine sobre ese tema. El facilitador se convierte en el observante del proceso y en el administrador del Foro, leyendo y analizando la calidad de las diferentes ponencias de sus estudiantes.

Para efectos de todo el proceso de evaluación y realimentación que puedan recibir los estudiantes, por parte de los facilitadores, se deben tener en cuenta los aportes de calidad, por parte de ellos. El escribir mucho o varias páginas no, necesariamente, se traduce en calidad. Ser concretos y precisos sería una cualidad deseable de una persona que aporte una idea escrita en un Foro.

La evaluación pretende que el facilitador recoja una serie de elementos, hechos, alguna situación de carácter importante, algún fenómeno o datos relevantes de las distintas ponencias del estudiante, y analizarlos, para, posteriormente, emitir un juicio valorativo sobre su aporte.

Al escribir o dar una opinión en un Foro, el estudiante tiene más tiempo para responder, pues sabe que esta respuesta es de tipo asincrónica, es decir, en horas o días diferentes, dentro del lapso establecido por el facilitador. Esto permite que la opinión sea mejor pensada, reflexionada y de calidad, porque puede consultar información pertinente, en el momento que se realimenta y apoya con las lecturas de las otras opiniones del mismo foro.

\section{CmapTools}

Este recurso digital, entre otras de las posibilidades que ofrece en sus aplicaciones didácticas, permite realizar presentaciones iníciales de un tema. En este caso, el mapa no será exhaustivo, sino que funcionará más a modo de una estructura, de un organizador previo de contenidos, el cual, posteriormente, irá siendo construido por el o los estudiantes.

Se pueden establecer límites en los conceptos y las relaciones del tema que se deba exponer o desarrollar durante la etapa presencial. En muchas ocasiones, los facilitadores se entusiasman, hasta tal punto, con la trascendencia o las implicaciones de un determinado tema, que nos resulta muy difícil decidir no explicar algunas de las cuestiones relacionadas. El mapa agiliza esta tarea del facilitador, al mismo tiempo que favorece el trabajo de comprensión en los estudiantes.

Otra de las utilidades más significativas del mapa conceptual para el facilitador, es la evaluación y el seguimiento del aprendizaje del estudiante. El mapa se puede utilizar tanto para la evaluación inicial y para diagnosticar los conocimientos previos del estudiante, como también para la evaluación formativa realizada durante el proceso didáctico o igual, es posible que se pueda utilizar en la evaluación sumativa realizada al final del proceso, con el fin de valorar el grado de aprendizaje.

Específicamente en la enseñanza, éste facilita la organización lógica y estructurada de los contenidos de aprendizaje porque son útiles para seleccionar, extraer y separar la información considerada relevante de la superficial. Esto permite interpretar, comprender e inferir con mayor certeza los datos analizados.

Desarrollan ideas y conceptos por medio de un aprendizaje interrelacionado, pudiendo precisar si un concepto es, en sí, válido e importante y si hacen falta enlaces, lo cual permitiría determinar la necesidad de investigar y de profundizar en el contenido. 


\section{Reflexión final}

Es necesario que en estos tiempos se promueva el uso de estos recursos didácticos digitales en los estudiantes y en los profesores, para que puedan ser introducidos correctamente en un entorno colaborativo. Es decir, si estos medios se emplearan cada vez más en los procesos de enseñanza y de aprendizaje, por medio de metodologías dinámicas de innovación, se generaría una nueva forma de pensar altamente necesaria, sobre todo, en épocas en las que vamos encaminados hacia una cultura tecnológica.

Por ello, se considera que el docente como un ente facilitador del proceso de aprendizaje tiene que asumir los grandes retos de esos cambios que enmarcan a la sociedad actual en el campo de las tecnologías. Y es que, además, basta con estar en permanente comunicación con los diferentes medios para darnos cuenta de la aparición de nuevos recursos digitales, los que, cada vez, son más complejos. Y es, en este sentido, que el docente debe estar en una renovación constante, de tal forma, que responda a las necesidades y a las exigencias que demanda la sociedad.

La revolución científico-técnica ha llegado a transformar los procesos educativos, ha brindado nuevas alternativas para hacer más eficaz los procesos de enseñanza y de aprendizaje; tenemos a la mano muchos de esos recursos para, realmente, revolucionar la educación, por eso resulta un reto para toda persona que debe enseñar y aprender, el hacer uso de esos medios. El reto es aprender a usarlos y para ello hay que tomar la decisión de usarlos para facilitar el proceso educativo y, sobre todo, romper con el paradigma de que sólo se puede aprender con medios y recursos que ofrece la educación presencial.

Sin embargo, el compromiso de toda persona que desee, verdaderamente, seguir educando y formando seres humanos, debe ser el de mantener una perspectiva de aplicar los principios humanistas; a pesar de que el contacto humano varía con la aplicación de estos recursos. Por eso es que el facilitador debe buscar siempre el cultivo de los valores y la convivencia humana, para que la tecnología no nos robe esa sensibilidad que nos hace sentir que estamos vivos, luchando juntos por ser mejores.

Si somos conscientes de que estos recursos didácticos digitales se aplican como estrategias para la innovación dentro del proceso de enseñanza, y si hay una clara mediación pedagógica, nos aseguraremos aprendizajes significativos en nuestros estudiantes.

\section{Referencias bibliográficas}

Basterrechea, J. (2007). Integración de los recursos didácticos digitales en la enseñanza del español: Hacia un nuevo paradigma. Recuperado el 19 de junio de 2007, de http://cvc.cervantes.es/ obref/congresos/rosario/ponencias/internacional/basterrechea_j.htm\#Arriba

Escamilla, J. (2003 reimp.) Selección y uso de tecnología educativa. (5 ${ }^{\mathrm{a}}$ Reimp.) México, D.F. Trillas.

Townsend, R. (2000). El reto tecnológico. Recuperado el 12 de junio de 2007, de http://wzar.unizar. es/acad/fac/egb/educa/jlbernal/Retec.html 


\section{Otras fuentes consultadas}

Ausubel, D., J. D. Novak., y Hanesian, H. (1986). Psicología educativa: un punto de vista cognoscitivo. ( $2^{\mathrm{a}}$ ed.). México, D.F.: Trillas.

Conejo, M. (2002) Blogs. Usos didácticos. Recuperado el 25 de julio de 2009, de http://cprmerida. juntaextremadura.net/

Gallego, A. (2006). Guías fáciles de las TIC-Blogs. Colegio Oficial de Ingenieros de la Telecomunicación. Recuperado el 25 de julio de 2009, de http://www.coit.es/pub/ficheros/ blogs 425672d7.pdf

García, A. (2006). Blogs y Wikis en tareas educativas. Recuperado el 25 de julio de 2009, de http:// observatorio.cnice.mec.es/modules.php?op=modload $\&$ name $=$ News $\&$ file $=$ article $\&$ sid $=378$

Institute For Human and Machine Cognition. (actualizado en enero 2009) CmapTools. Recuperado el 25 de julio de 2009.

Learning Management System, Moodle. (s.f). Usos didácticos del Wiki. Recuperado el 25 de julio de 2009, de http://docs.moodle.org/es/Usos did\%C3\%A1cticos del Wiki

Learning Management System, Moodle. (s.f.). Usos didácticos de los Foros. Recuperado el 25 de julio de 2009, de http://docs.moodle.org/es/Usos did\%C3\%A1cticos de los Foros

Ornelas, D. (10 de noviembre, 2007). El uso del Foro de Discusión Virtual en la enseñanza. Revista Iberoamericana de Educación, Vol. 44 (4), 12 y 22.

Vargas, E. (1998). Metodología de la enseñanza de las Ciencias Naturales. San José, Costa Rica: EUNED.

Viñas, F., Villar, E., Caparrós, B., Juan, J, Perez, I., y Cornellá, M. (2002). Internet y Psicopatología: El uso del CHAT y su relación con diferentes índices de psicopatología. Recuperado el 10 de agosto de 2009, de http://www.psiquiatria.com/articulos/psiq general y otras areas/inter$\underline{\text { net } / 4837 /}$ 